\title{
Multivariate Analysis and Validation of the Prognostic Factors for Skull Base Chordoma
}

\author{
Chubei Teng ${ }^{1,2,3}$, Qi Yang ${ }^{1,2}$, Zujian Xiong ${ }^{1,2}$, Ningrong Ye ${ }^{1,2}$ and Xuejun Li ${ }^{1,2 *}$ \\ ${ }^{1}$ Department of Neurosurgery, Xiangya Hospital, Central South University, Changsha, China, ${ }^{2}$ Hunan International Scientific \\ and Technological Cooperation Base of Brain Tumor Research, Xiangya Hospital, Central South University, Changsha, China, \\ ${ }^{3}$ Department of Neurosurgery, The First Affiliated Hospital, University of South China, Hengyang, China
}

Background: Skull base chordoma is a rare tumor with low-grade malignancy and a high recurrence rate, the factors affecting the prognosis of patients need to be further studied. For that, we investigated prognostic factors of skull base chordoma through the database of the Surveillance, Epidemiology, and End Results (SEER) program, and validated in an independent data set from the Xiangya Hospital.

Methods: Six hundred and forty-three patients diagnosed with skull base chordoma were obtained from the SEER database (606 patients) and the Xiangya Hospital (37 patients). Categorical variables were selected by Chi-square test with a statistical difference. Survival curves were constructed by Kaplan-Meier analysis and compared by log-rank test. Univariate and multivariate Cox regression analyses were used to explore the prognostic factors. Propensity score matching (PSM) analysis was undertaken to reduce the substantial bias between gross total resection (GTR) and subtotal resection (STR) groups. Furthermore, clinical data of 37 patients from the Xiangya Hospital were used as validation cohorts to check the survival impacts of the extent of resection and adjuvant radiotherapy on prognosis.

Results: We found that age at diagnosis, primary site, disease stage, surgical treatment, and tumor size was significantly associated with the prognosis of skull base chordoma. PSM analysis revealed that there was no significant difference in the OS between GTR and STR $(p=0.157)$. Independent data set from the Xiangya Hospital proved no statistical difference in OS between GTR and STR groups $(p=0.16)$, but the GTR group was superior to the STR group for progression-free survival (PFS) $(p=0.048)$. Postoperative radiotherapy does not improve OS $(p=0.28)$, but it can prolong PFS $(p=$ 0.0037). Nomograms predicting 5- and 10-year OS and DSS were constructed based on statistically significant factors identified by multivariate Cox analysis. Age, primary site, tumor size, surgical treatment, and disease stage were included as prognostic predictors in the nomograms with good performance.

Accepted: 18 October 2021 Published: 23 November 2021

Citation:

Teng C, Yang Q, Xiong Z, Ye $N$ and LiX (2021) Multivariate Analysis and Validation of the Prognostic Factors for Skull Base Chordoma. Front. Surg. 8:764329. doi: 10.3389/fsurg.2021.764329
Conclusions: We identified age, tumor size, surgery, primary site, and tumor stage as main factors affecting the prognosis of the skull base chordoma. Resection of the tumor as much as possible while ensuring safety, combined with postoperative radiotherapy may be the optimum treatment for skull base chordoma.

Keywords: gross total resection, nomogram, SEER program, skull base chordoma, subtotal resection 


\section{INTRODUCTION}

Chordoma, derived from embryonic notochord remnant tissue, is a low-grade malignant tumor, with an incidence of about $0.08 / 100,000$ (1). It accounts for $1-4 \%$ of all primary bone tumors and mainly occurs in the axial bone of the skull base region (32\%), the sacrococcygeal region (29.2\%), the spine (32.8\%), and the other $6.0 \%$ chordoma were found outside the axial bone (2). As its special location and relatively poor prognosis, skull base chordoma which usually occurs in the spheno-occipital region is the research hotspot among chordoma.

The pathology of skull base chordoma does not show many characteristics of malignancy tumors, and the tumor proliferation rate is not high, but local invasiveness is strong and the recurrence rate is high (3). Due to the skull base chordoma's slow progressive growth and lack of specific symptoms in the early stage, the tumor is often quite large when symptoms appear. Surgical resection is the primary choice for the treatment of skull base chordoma; however, its deep site which is adjacent to the brain stem, important cranial nerves, and intracranial vessels makes it difficult for surgeons to remove the tumor safely and completely. Radiotherapy is an important adjuvant treatment, chordoma is insensitive for low-dose radiotherapy, it needs highdose radiotherapy to kill tumor cells, but high doses of radiation may damage surrounding brain tissue and nerves, limiting the use of radiotherapy in chordoma treatment (4). However, the median survival of patients who have received treatments was 6.29-years, the 5- and 10-year survival rates were 67.6 and $39.9 \%$, respectively (5). Therefore, it is necessary to explore the prognostic factors for skull base chordoma.

Previous studies have shown that factors affecting prognosis include patient's age, tumor size, tumor site, and vascular involvement (5-7). Meanwhile, some molecular markers such as high expression of Ki-67 and MIB-1 are associated with poor prognosis and high recurrence rate $(8-10)$. However, the effect of the extent of surgical resection on skull base chordoma prognosis is not clear and needs to be further studied. On the one hand, aggressive total resection may lead to serious complications that may reduce the survival rate, and different centers reported different total resection rates, the average total resection rate being only $24-52 \%(11-13)$. On the other hand, incomplete resection will increase the recurrence rate (14). Therefore, whether gross total resection (GTR) is necessary and whether subtotal resection (STR) will affect the survival rate remains to be further studied.

In this study, we analyzed prognostic factors in 606 patients with skull base chordoma based on clinical data from the Surveillance Epidemiology and End Results (SEER) database sponsored by the American Cancer Institute, with a focus on evaluating the effect of surgical resection extent and radiotherapy on patients' prognosis. After that, we brought in clinical data from our center to validate our findings. Furthermore, we attempted to establish prediction models using the line diagram. A flow chart was drawn to show the data collection and analysis procedure in this study (Figure 1). By this study, we hope to provide treatment strategies for clinicians and serve as a basis for further research on skull base chordoma.

\section{MATERIALS AND METHODS}

\section{Data Collection and Processing}

Patients with a diagnosis of skull base chordoma between 1973 and 2016 were selected from the SEER database (SEER*Stat software version 8.3.6). The International Classification of Diseases for Oncology Third Edition (ICD-O-3) was used to identify histologically confirmed cases of chordoma, chondroid chordoma, and dedifferentiated chordoma with the codes 9370 , 9371, and 9372. Chordomas in the bones of skull and face (C41.0), brain (C71.0-71.9), pituitary gland (C75.1), or other head structures (C10.0-C10.9, C11.0-C11.9, C14.0, C30.0, C31.3, C31.9, C49.0, C70.0, C72.5, C76.0), were taken to represent skull base lesions. Information of patients, including age at diagnosis, race, gender, year of diagnosis, marital status, primary tumor sites, tumor size, disease stage, radiation record, chemotherapy record, follow-up information, and extent of surgical resection, was collected in this study. According to the information on the extent of surgical resection obtained from the SEER database, we characterized "total resection," "radical resection," and "gross resection" as GTR, and "local excision," "partial excision," and "subtotal resection" as STR. Patients who were coded as "not primary or first tumor" and "surgery not otherwise specified" were excluded from the survival analysis.

To validate the results of the SEER cohort, 37 patients who have been diagnosed with skull base chordoma and received surgery at the Xiangya Hospital between 2010 and 2020 were selected for retrospective analysis. The study was approved by the Ethics Committee of Xiangya Hospital of Central South University (IRB NO. 202012229). Written informed consent for patients included in the study was obtained. The extent of surgical resection was determined based on postoperative imaging data and surgical records. GTR was defined as total resection of the tumor with no image contrast-enhanced, STR was defined as incomplete resection of the tumor with more than $90 \%$ resection (15). Patients were followed up until February 2021. Overall survival (OS) is defined as the time from the date of surgery to death/last follow-up. Progression-free survival (PFS) is defined as the time between surgery and tumor progression, recurrence, or death.

\section{Statistical Analysis and Propensity Score Matching}

We calculated the statistical differences of categorical variables by Chi-square test. Survival curves were constructed by KaplanMeier analysis with a log-rank test. Prognostic factors were identified based on univariate and multivariate Cox hazard models. Multivariate Cox proportional hazard models were constructed using a stepwise backward method. To accurately predict the OS and disease-specific survival (DSS) rates of patients with skull base chordomas, we established a prognostic nomogram system. Index of concordance (C-index) and internal validation were performed to evaluate the predictive power of the nomogram.

For reducing the substantial bias in patients selection between different groups (STR group and GTR group), we used PSM analysis, which can better evaluate the 


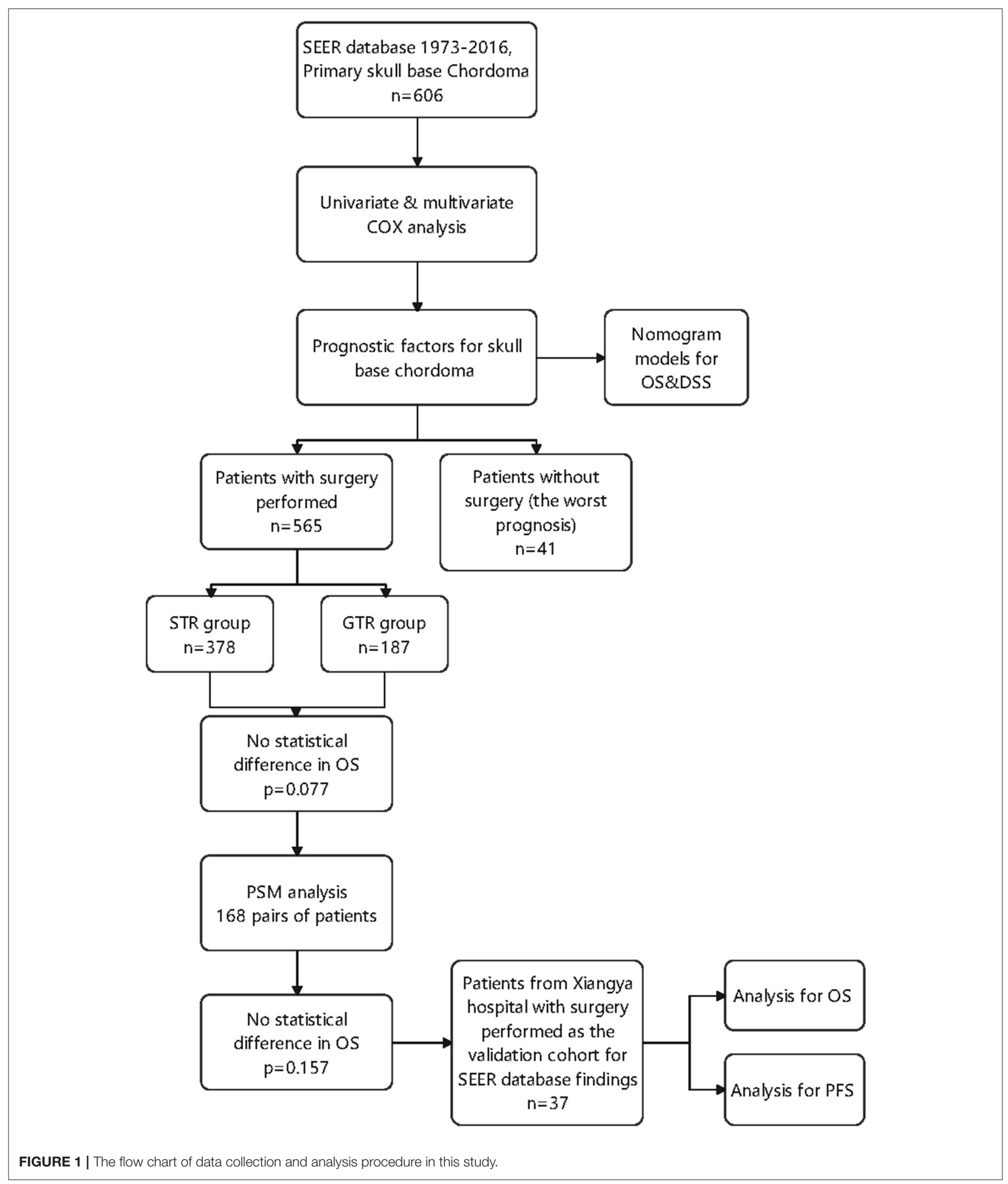

therapeutic strategies by processing relevant covariables that might affect survival independent of the extent of resection. Propensity scores were estimated using a logistic regression model based on both covariables including 
TABLE 1 | Characteristics of 606 patients with skull base chordoma tumors registered in SEER database (1973-2016).

\begin{tabular}{|c|c|}
\hline Patients, $n$ & 606 \\
\hline Median age, years (range) & $47(0-92)$ \\
\hline Mean age, years ( \pm SD) & $45.5(19.3)$ \\
\hline Median follow-up time, months (range) & $59(0-343)$ \\
\hline \multicolumn{2}{|l|}{ Age (years) } \\
\hline$<18$ & $60(9.9 \%)$ \\
\hline 18-39 & 169 (27.9\%) \\
\hline $40-59$ & $229(37.8 \%)$ \\
\hline $60-79$ & $133(21.9 \%)$ \\
\hline $80+$ & $15(2.5 \%)$ \\
\hline Year of Diagnosis & 2007 median year (2006 mean) \\
\hline 1973-1999 & $119(19.6 \%)$ \\
\hline 2000-2009 & $246(40.6 \%)$ \\
\hline $2010-2016$ & $241(39.8 \%)$ \\
\hline \multicolumn{2}{|l|}{ Gender } \\
\hline Male & $332(54.8 \%)$ \\
\hline Female & $274(45.2 \%)$ \\
\hline \multicolumn{2}{|l|}{ Race } \\
\hline White & $486(80.2 \%)$ \\
\hline Black & $33(5.4 \%)$ \\
\hline Others & $87(14.4 \%)$ \\
\hline \multicolumn{2}{|l|}{ Married } \\
\hline Unmarried & $182(30 \%)$ \\
\hline Married & $404(66.7 \%)$ \\
\hline Unknown & $20(3.3 \%)$ \\
\hline \multicolumn{2}{|l|}{ Registry } \\
\hline Low volume (<30 skull base patients) & $153(25.2 \%)$ \\
\hline High volume ( $\geq 30$ skull base patients) & $453(74.8 \%)$ \\
\hline \multicolumn{2}{|l|}{ Histological Subtype } \\
\hline Chordoma & $541(89.3 \%)$ \\
\hline Chondroid chordoma & $64(10.6 \%)$ \\
\hline Dedifferentiated chordoma & $1(0.1 \%)$ \\
\hline \multicolumn{2}{|l|}{ Primary Site } \\
\hline Bones of skull and face & $440(72.6 \%)$ \\
\hline Brain & $79(13 \%)$ \\
\hline Pituitary gland & $34(5.6 \%)$ \\
\hline Others & $53(8.8 \%)$ \\
\hline \multicolumn{2}{|l|}{ Disease Stage } \\
\hline Localized & $262(43.2 \%)$ \\
\hline Regional & $233(38.4 \%)$ \\
\hline Distant & $58(9.6 \%)$ \\
\hline Unknown & $53(8.8 \%)$ \\
\hline \multicolumn{2}{|l|}{ Surgery } \\
\hline No surgery performed & $41(6.7 \%)$ \\
\hline STR & $378(62.4 \%)$ \\
\hline GTR & 187 (30.9\%) \\
\hline \multicolumn{2}{|l|}{ Radiation } \\
\hline No & 305 (50.3\%) \\
\hline Yes & $301(49.7 \%)$ \\
\hline \multicolumn{2}{|l|}{ Chemotherapy } \\
\hline No & $592(97.7 \%)$ \\
\hline
\end{tabular}

(Continued)
TABLE 1 | Continued

\begin{tabular}{lc}
\hline Yes & $14(2.3 \%)$ \\
Treatment Combination & $24(3.9 \%)$ \\
None & $170(28.1 \%)$ \\
STR only & $180(29.7 \%)$ \\
STR+Radiation & $111(18.3 \%)$ \\
GTR only & $104(17.2 \%)$ \\
GTR+Radiation & $17(2.8 \%)$ \\
Radiation only & \\
Tumor Size (cm) & $58(9.6 \%)$ \\
0-2 & $197(32.4 \%)$ \\
2-4 & $110(18.2 \%)$ \\
4-6 & $49(8.1 \%)$ \\
$>6$ & $192(31.7 \%)$ \\
Unknown & \\
Overall Survival (\%) & 76.8 \\
5-Year Overall Survival & 61.8 \\
10-Year Overall Survival & \\
Tumor-specific Survival (\%) & 69.9 \\
5-Year Tumor-specific Survival & \\
10-Year Tumor-specific Survival & \\
\hline
\end{tabular}

GTR, gross total resection; STR, subtotal resection.

age, year of diagnosis, gender, race, marital status, registry, histological subtype, primary site, disease stage, radiotherapy, chemotherapy, and tumor size that might affect survival independent of the extent of resection. A 1:1 nearest neighbor matching without replacement was used with a caliper width of 0.05 .

Chi-square tests and Cox regression were analyzed using the SPSS version 22.0 (IBM SPSS Statistics, Chicago, IL, United States), and $p<0.05$ was considered statistically significant. Kaplan-Meier curves, nomogram, and PSM analysis were undertaken with the $\mathrm{R}$ studio based on $\mathrm{R}$ software (version 3.6.2). All $p$-values were two tailed.

\section{RESULTS}

\section{Overview of the Clinical Traits of Patients With Skull Base Chordoma}

SEER database is a clinical follow-up database with a long time period and large sample size in multiple centers. However, skull base chordoma is a rare disease, a total of 606 patients with skull base chordoma were identified in the SEER database. There were 332 male patients (54.8\%) and 274 female patients (45.2\%). The age of patients ranged from 0 to 92 years, and the median age at diagnosis was 47 years. Patients aged $40-59$ years comprised the largest proportion, accounting for $37.8 \%$, and patients aged below 18 years comprised $9.9 \%$. The median year of diagnosis was 2007, and the median follow-up time was 59 months (range 0-343 months). All selected cases were registered across 17 centers, of which the majority (453 patients, $74.8 \%$ ) were treated in high-volume registries ( $\geq 30$ skull base 
TABLE 2 | Univariate and multivariate analysis of the prognostic factors of patients with primary skull base chordoma.

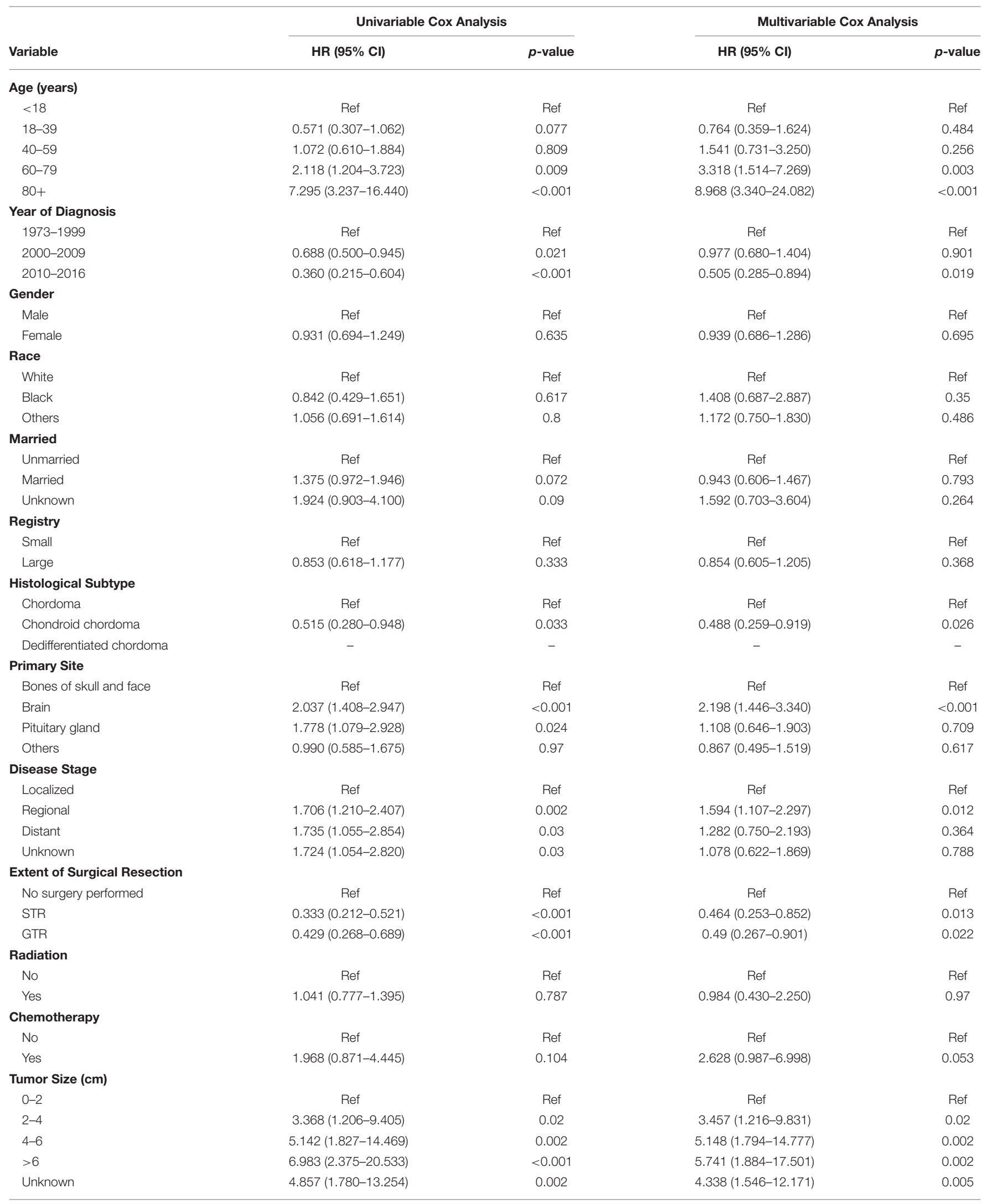

GTR, gross total resection; STR, subtotal resection. 

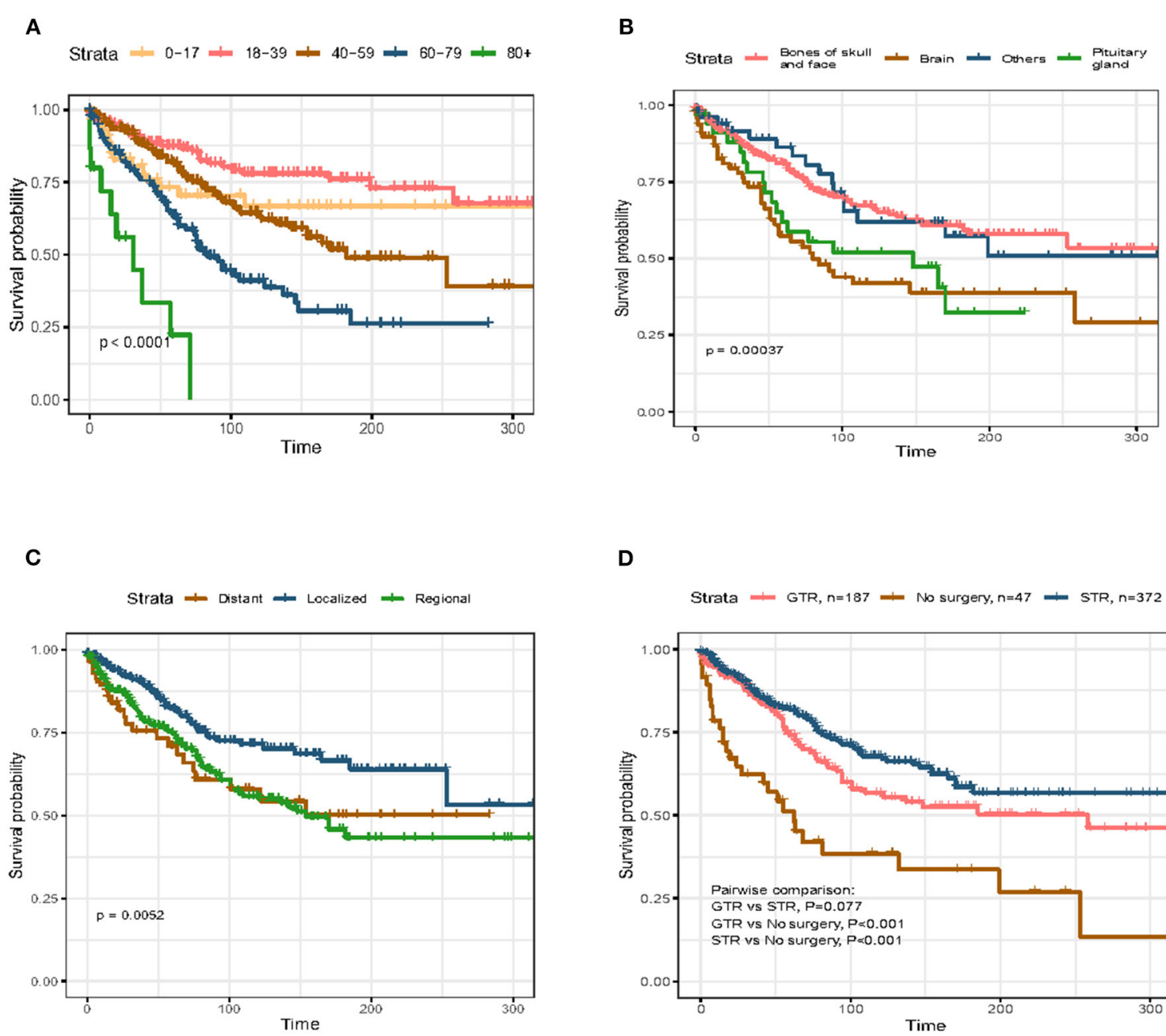

D
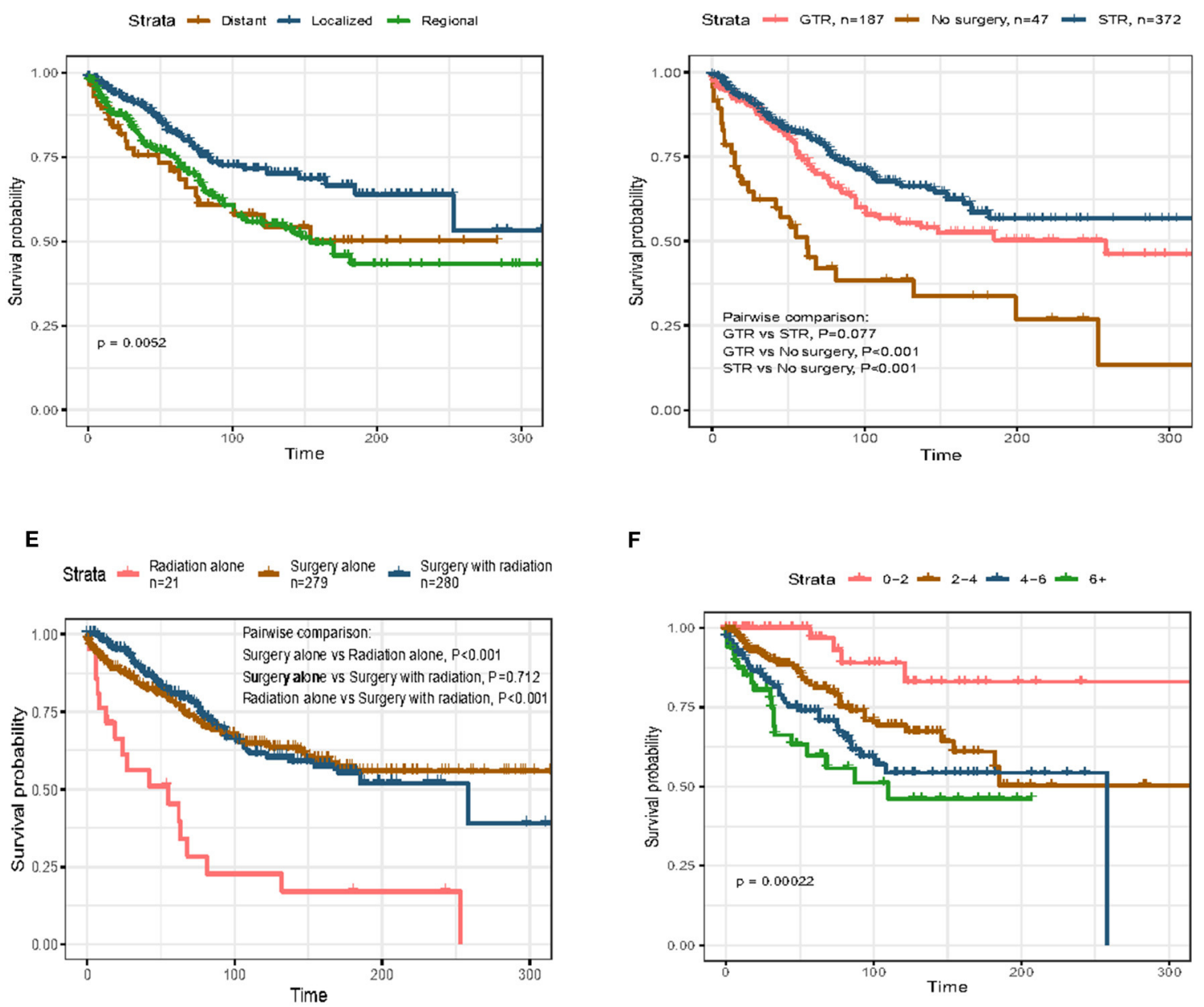

$\mathbf{F}$

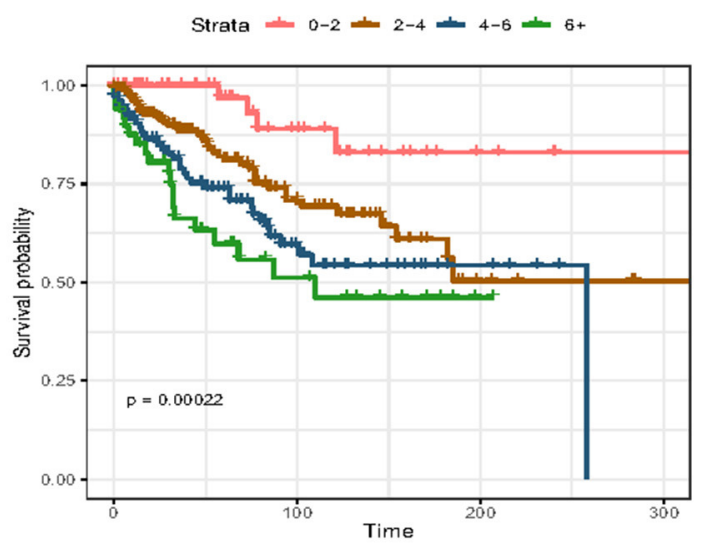

FIGURE 2 | Kaplan-Meier curves (K-M curves) of overall survival (OS) in skull base chordoma patients stratified by (A) age, (B) primary site, (C) disease stage, (D) surgery, (E) therapy, and (F) tumor size.

chordoma patients). Meanwhile, 41 patients did not undergo surgery (6.7\%), 378 patients were treated with STR (62.4\%), and 187 patients were treated with GTR (30.9\%). Nearly half of the patients $(49.7 \%)$ received radiation treatment. Tumor size 
TABLE 3 | Comparison of patients with skull base chordomas receiving GTR or STR.

\begin{tabular}{|c|c|c|c|}
\hline Postoperative Radiation & GTR & STR & $P$-value \\
\hline Total number of patients & 187 & 378 & \\
\hline Age (years) & & & 0.362 \\
\hline$<18$ & $17(9.1 \%)$ & 41 (10.9\%) & \\
\hline $18-39$ & $51(27.3 \%)$ & $109(28.8 \%)$ & \\
\hline $40-59$ & 70 (37.4\%) & $147(38.9 \%)$ & \\
\hline $60-79$ & $42(22.5 \%)$ & 76 (20.1\%) & \\
\hline $80+$ & 7 (3.7\%) & $5(1.3 \%)$ & \\
\hline Year of Diagnosis & & & 0.037 \\
\hline 1973-1999 & 47 (28.1\%) & $61(16.1 \%)$ & \\
\hline 2000-2009 & 72 (38.5\%) & 159 (42.1\%) & \\
\hline 2010-2016 & $68(36.4 \%)$ & 158 (41.8\%) & \\
\hline Gender & & & 0.915 \\
\hline Male & 103 (55.1\%) & 210 (55.6\%) & \\
\hline Female & 84 (44.9\%) & $168(44.4 \%)$ & \\
\hline Race & & & 0.020 \\
\hline White & $151(80.7 \%)$ & 300 (79.3\%) & \\
\hline Black & $16(8.6 \%)$ & $15(4 \%)$ & \\
\hline Others & $20(10.7 \%)$ & $63(16.7 \%)$ & \\
\hline Marital Status & & & 0.833 \\
\hline Unmarried & 56 (30\%) & $117(30.9 \%)$ & \\
\hline Married & $125(66.8 \%)$ & $252(66.7 \%)$ & \\
\hline Unknown & $6(3.2 \%)$ & $9(2.4 \%)$ & \\
\hline Registry & & & 0.578 \\
\hline Small & $43(23 \%)$ & 95 (25.1\%) & \\
\hline Large & $144(77 \%)$ & $283(74.9 \%)$ & \\
\hline Histological Subtype & & & 0.780 \\
\hline Chordoma & 167 (89.3\%) & 337 (89.1\%) & \\
\hline Chondroid chordoma & 20 (10.7\%) & $40(10.6 \%)$ & \\
\hline $\begin{array}{l}\text { Dedifferentiated } \\
\text { chordoma }\end{array}$ & $0(0 \%)$ & $1(0.3 \%)$ & \\
\hline Primary Site & & & 0.180 \\
\hline Bones of skull and face & $126(67.4 \%)$ & 287 (75.9\%) & \\
\hline Brain & 29 (15.5\%) & $42(11.1 \%)$ & \\
\hline Pituitary gland & $14(7.5 \%)$ & $19(5 \%)$ & \\
\hline Others & $18(9.6 \%)$ & $30(8 \%)$ & \\
\hline Disease Stage & & & 0.052 \\
\hline Localized & 74 (39.6\%) & $182(48.1 \%)$ & \\
\hline Regional & 73 (39\%) & $145(38.4 \%)$ & \\
\hline Distant & $24(12.8 \%)$ & $26(6.9 \%)$ & \\
\hline Unknown & $16(8.6 \%)$ & $25(6.6 \%)$ & \\
\hline Radiotherapy & & & 0.721 \\
\hline No & 95 (50.8\%) & $186(49.2 \%)$ & \\
\hline Yes & 92 (49.2\%) & 192 (50.8\%) & \\
\hline Chemotherapy & & & 0.986 \\
\hline No & 183 (97.9\%) & 370 (97.9\%) & \\
\hline Yes & $4(2.1 \%)$ & $8(2.1 \%)$ & \\
\hline Tumor Size (cm) & & & 0.327 \\
\hline $0-2$ & 19 (10.1\%) & 108 (28.6\%) & \\
\hline $2-4$ & 58 (31.0\%) & 39 (10.3\%) & \\
\hline $4-6$ & 31 (16.5\%) & 135 (35.7\%) & \\
\hline
\end{tabular}

(Continued)
TABLE 3 | Continued

\begin{tabular}{lccc}
\hline Postoperative Radiation & GTR & STR & P-value \\
\hline$>6$ & $19(10.1 \%)$ & $73(19.3 \%)$ & \\
$\quad$ Unknown & $60(32.0 \%)$ & $23(6.1 \%)$ & \\
Overall Survival (\%) & & & 0.104 \\
$\quad$ 5-Year Overall Survival & 74.1 & 81.2 & \\
$\quad$ 10-Year Overall Survival & 56.6 & 67.0 & \\
Tumor-specific Survival & & & 0.316 \\
(\%) & & & \\
5-Year Tumor-specific & 81.7 & 84.3 & \\
$\quad$ Survival & & & \\
10-Year Tumor-specific & 65.6 & 74.5 & \\
$\quad$ Survival & & & \\
\hline
\end{tabular}

GTR, gross total resection; STR, subtotal resection.

information was available for 414 of 606 patients. The tumor size of most patients was $2-4 \mathrm{~cm}(47.6 \%)$. The 5- and 10 -year OS rates of all patients were 76.8 and $61.8 \%$, respectively. The 5- and 10-year DSS rates were 81.6 and 69.9\%, respectively. The baseline characteristics of these patients are listed in Table 1.

\section{Survival Analysis and Prognostic Factor Identification}

Survival analysis based on univariate and multivariate Cox analyses was performed on all selected patients. The results showed that age at diagnosis, primary site, disease stage, tumor size, and whether or not undergo surgery were closely related to the prognosis of primary skull base chordoma ( $p<0.05)$, as shown in Table 2. Multivariate analyses demonstrated that age [ $>80$ years, hazard ratio $(\mathrm{HR})=8.968,95 \% \mathrm{CI}=3.34-24.082$, $p<0.001 ; 60-79$ years, $\mathrm{HR}=3.318,95 \% \mathrm{CI}=1.514-7.269, p$ $<0.003$ ], primary site (brain, $\mathrm{HR}=2.198,95 \% \mathrm{CI}=1.446-$ $3.34, p<0.001$ ), disease stage (regional, $\mathrm{HR}=1.594,95 \% \mathrm{CI}$ $=1.107-2.297, p=0.012)$, tumor size $(2-4 \mathrm{~mm}, \mathrm{HR}=3.457$, $95 \% \mathrm{CI}=1.216-9.831, p=0.02 ; 4-6 \mathrm{~mm}, \mathrm{HR}=5.148,95 \% \mathrm{CI}=$ $1.794-14.777, p=0.002$; $>6 \mathrm{~mm}, \mathrm{HR}=5.741,95 \% \mathrm{CI}=1.884-$ $17.501, P=0.002$ ), and whether or not undergo surgery (STR, $\mathrm{HR}=0.464,95 \% \mathrm{CI}=0.253-0.852, p=0.013 ; \mathrm{GTR}, \mathrm{HR}=0.49$, $95 \% \mathrm{CI}=0.267-0.901, p=0.022)$ were independent prognostic factors for OS (Table 2). To illustrate the relationship between different risk factors and survival prognosis, the survival curves were drawn using the Kaplan-Meier analysis (Figure 2).

Survival analysis showed no significant difference in OS between patients receiving GTR and those receiving STR ( $p=$ 0.077; Figure 2D). As the distributions of the year of diagnosis and patients' race were significantly different between the GTR and STR groups ( $p=0.037$ and $p=0.020$, respectively; Table 3 ), PSM was conducted to minimize the selection bias (Table 4). Subsequently, 168 pairs of patients were generated and both covariables entered in PSM were balanced (all $p>0.05$ ). After PSM, the OS difference between patients with GTR and those with STR was still insignificant $(p=0.157)$. The 5 - and 10 year OS rates of patients with GTR were 74.5 and $54.7 \%$, and 
TABLE 4 | Comparison of patients with skull base chordomas receiving GTR or STR after propensity score matching.

\begin{tabular}{|c|c|c|c|}
\hline Postoperative Radiation & GTR & STR & $P$-value \\
\hline Total number of patients & 168 & 168 & \\
\hline Age (years) & & & 0.950 \\
\hline$<18$ & 17 (10.1\%) & $18(10.7 \%)$ & \\
\hline $18-39$ & 48 (28.6\%) & $45(26.8 \%)$ & \\
\hline $40-59$ & $61(36.3 \%)$ & $63(37.5 \%)$ & \\
\hline $60-79$ & 37 (22\%) & 39 (23.2\%) & \\
\hline $80+$ & $5(3 \%)$ & $3(1.8 \%)$ & \\
\hline Year of Diagnosis & & & 0.856 \\
\hline 1973-1999 & 35 (20.8\%) & $33(19.6 \%)$ & \\
\hline 2000-2009 & 66 (39.3\%) & $71(42.3 \%)$ & \\
\hline 2010-2016 & 67 (39.9\%) & 64 (38.1\%) & \\
\hline Gender & & & 1 \\
\hline Male & 94 (56\%) & 94 (56\%) & \\
\hline Female & $74(44 \%)$ & $74(44 \%)$ & \\
\hline Race & & & 0.150 \\
\hline White & 134 (79.8\%) & 137 (81.5\%) & \\
\hline Black & $14(8.3 \%)$ & $6(3.6 \%)$ & \\
\hline Others & 20 (11.9\%) & 25 (14.9\%) & \\
\hline Marital Status & & & 0.775 \\
\hline Unmarried & 52 (30.9\%) & 50 (29.8\%) & \\
\hline Married & $110(65.5 \%)$ & $114(67.8 \%)$ & \\
\hline Unknown & $6(3.6 \%)$ & $4(2.4 \%)$ & \\
\hline Registry & & & 0.694 \\
\hline Small & 39 (23.2\%) & $36(21.4 \%)$ & \\
\hline Large & $129(76.8 \%)$ & $132(78.6 \%)$ & \\
\hline Histological Subtype & & & 0.736 \\
\hline Chordoma & $149(88.7 \%)$ & $147(87.5 \%)$ & \\
\hline Chondroid chordoma & 19 (11.3\%) & $21(12.5 \%)$ & \\
\hline $\begin{array}{l}\text { Dedifferentiated } \\
\text { chordoma }\end{array}$ & $0(0 \%)$ & $0(0 \%)$ & \\
\hline Primary Site & & & 0.889 \\
\hline Bones of skull and face & 122 (72.6\%) & $127(75.6 \%)$ & \\
\hline Brain & 20 (11.9\%) & 18 (10.7\%) & \\
\hline Pituitary gland & 12 (7.2\%) & $9(5.4 \%)$ & \\
\hline Others & 14 (8.3\%) & $14(8.3 \%)$ & \\
\hline Disease Stage & & & 0.326 \\
\hline Localized & 74 (44\%) & 75 (44.6\%) & \\
\hline Regional & $70(41.7 \%)$ & 67 (39.8\%) & \\
\hline Distant & $18(10.7 \%)$ & $13(7.8 \%)$ & \\
\hline Unknown & $6(3.6 \%)$ & $13(7.8 \%)$ & \\
\hline Radiotherapy & & & 0.445 \\
\hline No & $82(49 \%)$ & 89 (53\%) & \\
\hline Yes & 86 (51\%) & 79 (47\%) & \\
\hline Chemotherapy & & & 1 \\
\hline No & 164 (97.6\%) & 164 (97.6\%) & \\
\hline Yes & 4 (2.4\%) & 4 (2.4\%) & \\
\hline Tumor Size (cm) & & & 0.452 \\
\hline $0-2$ & 53 (31.6\%) & 59 (35.1\%) & \\
\hline $2-4$ & 18 (10.7\%) & $16(9.5 \%)$ & \\
\hline $4-6$ & 54 (32.1\%) & 51 (30.4\%) & \\
\hline
\end{tabular}

(Continued)
TABLE 4 | Continued

\begin{tabular}{lccc}
\hline Postoperative Radiation & GTR & STR & $P$-value \\
\hline$>6$ & $25(14.9 \%)$ & $32(19 \%)$ & \\
$\quad$ Unknown & $18(10.7 \%)$ & $10(6 \%)$ & \\
Overall Survival (\%) & & & 0.157 \\
$\quad$ 5-Year Overall Survival & 74.5 & 80.6 & \\
$\quad$ 10-Year Overall Survival & 54.7 & 65.3 & \\
$\begin{array}{l}\text { Tumor-specific Survival } \\
\text { (\%) }\end{array}$ & & & 0.475 \\
5-Year Tumor-specific & 82.4 & 83.2 & \\
$\quad$ Survival & & & \\
$\quad$ 10-Year Tumor-specific & 62.9 & 72.8 & \\
$\quad$ Survival & & & \\
\hline
\end{tabular}

GTR, gross total resection; STR, subtotal resection.

the 5- and 10-year OS rates of patients with STR were 80.6 and $65.3 \%$, respectively.

\section{Estimation of Identified Prognostic Factor Efficiency by Nomograms}

Nomograms predicting 5- and 10-year OS and DSS were constructed based on statistically significant factors identified by multivariate Cox analysis (Figure 3). Age, primary site, tumor size, surgical treatment, and disease stage were included as prognostic predictors in the nomograms. By adding the scores for each selected variable, the survival probability of each individual was easily calculated. The $\mathrm{C}$-indexes were high in both internal validations (OS: 0.764, 95\% CI, 0.733-0.795; DSS: 0.755, 95\% CI, $0.724-0.785)$. The calibration plots for the probability of OS and DSS at 5- and 10-years showed an optimal agreement between the prediction by nomogram and the actual observation (Figure 4).

\section{Validating the Impact of Surgical Resection and Adjuvant Radiotherapy in an Independent Data Set}

Another 37 skull base chordoma patients' clinical data from the Xiangya Hospital were used as the validation data set. the baseline characteristics of these patients are demonstrated in Table 5. According to the extent of surgical resection, 13 cases (35.1\%) underwent GTR and 24 cases (64.9\%) underwent STR. In addition, 22 patients $(59.5 \%)$ received stereotactic radiotherapy, while 15 patients (40.5\%) did not receive radiotherapy. Results of survival analysis showed no statistically significant difference in OS between GTR and STR groups ( $p=0.16$; Figure 5A). For PFS, the GTR group was superior to the STR group and the difference was statistically significant ( $p=0.048$; Figure $5 B$ ). There was no statistically significant difference in OS between patients who received stereotactic radiotherapy after surgery and those who did not receive radiotherapy ( $p=0.28$; Figure $5 \mathrm{C}$ ), while the PFS of patients who received radiotherapy was significantly better than that of patients who did not receive radiotherapy ( $p=$ 0.0037; Figure 5D). These results indicate that GTR does not appear to improve OS, but it is associated with improvements in PFS. At the same time, although postoperative radiotherapy does 


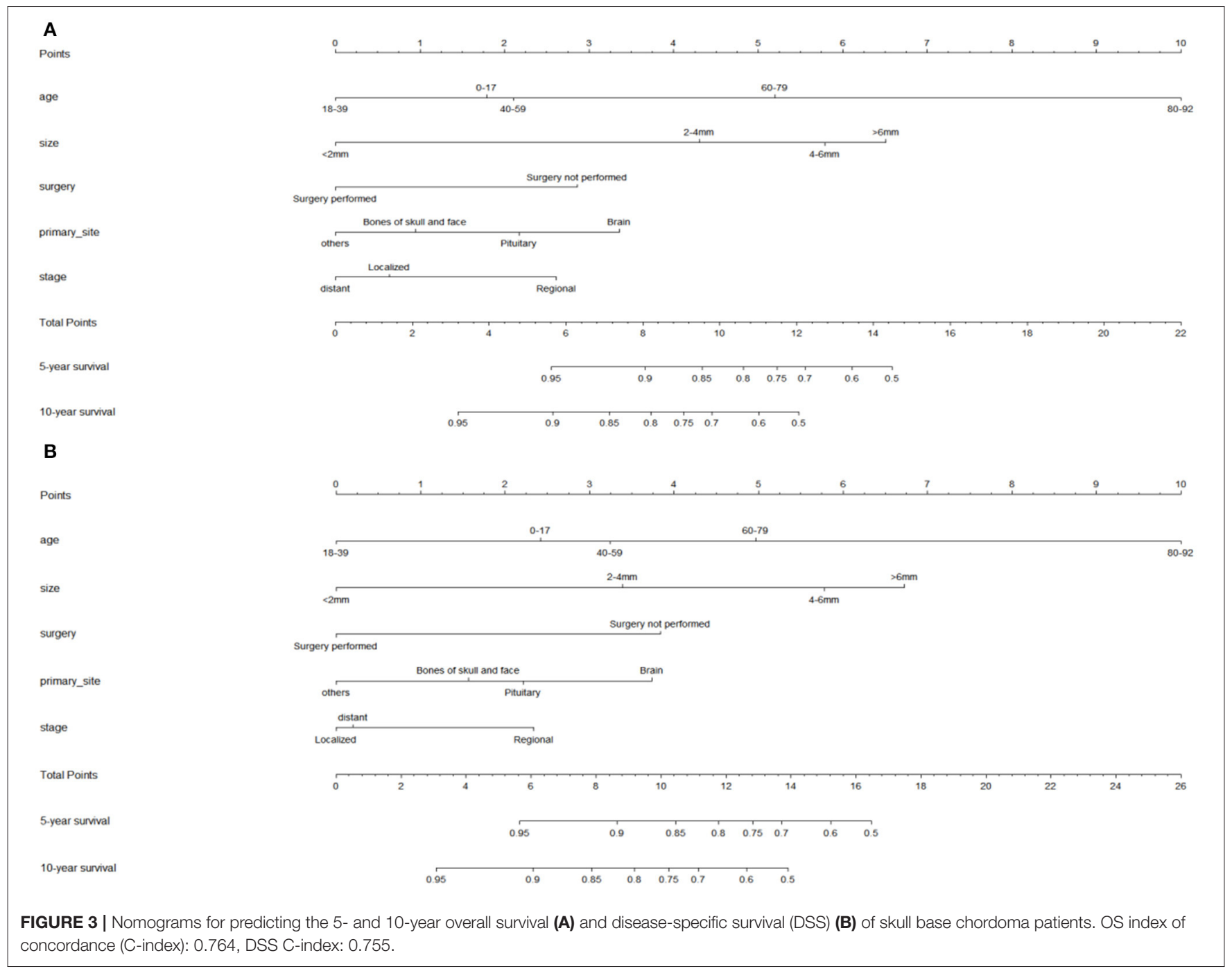

not improve OS, it can prolong the time of PFS and reduce the recurrence rate.

\section{DISCUSSION}

By analyzing 606 cases of skull base chordomas from the SEER database and validated by an independent data set from the Xiangya Hospital, this study found that the patient's age, tumor size, surgery, primary location, and tumor stage were closely related to the patient's prognosis $(5,6)$. Previous studies reported a different age of onset of skull base chordomas. Crockard reported that the average age was 58.1-years, while Al-Mefty reported an average age of 38.4-years, and $\mathrm{Wu}$ reported an average age of 35.3-years (16-18). Anyhow, age is an important factor affecting the patients' prognosis, and the prognosis of elderly patients is worse than that of young patients, for elderly patients are more likely to suffer recurrence and metastasis (16, 19). Moreover, elderly patients have poor tolerance to surgery and are more likely to have serious postoperative complications that affect prognosis. In addition, due to the slow growth of tumors and the larger space for intracranial compensation caused by brain atrophy in elderly patients, neurological symptoms tend to appear lately and atypically. When the symptom appears, the tumor is usually very large and has already adhered to the surrounding brain stem or important vessels and nerves. Such patients have a higher risk of surgical resection and tend to suffer serious complications (20).

Compared with sacrococcygeal chordoma, the prognosis of skull base chordoma is more sensitive to tumor size $(21,22)$. Tumor size is mainly related to tumor stage and classification. For example, the classification of Al-Mefty is defined as Type I: Small tumor with mild symptoms or no symptom and limited to a single anatomical space at the skull base (such as sphenoid sinus, cavernous sinus, inferior slope, or occipital condyle). Type II: The tumor is large and invades two or more anatomical spaces of the skull base, which can be removed through a skull base approach. Type III: Extensive infiltration of skull base multiple anatomical spaces, need to be combined with two or more skull base approaches for total resection of the tumor 

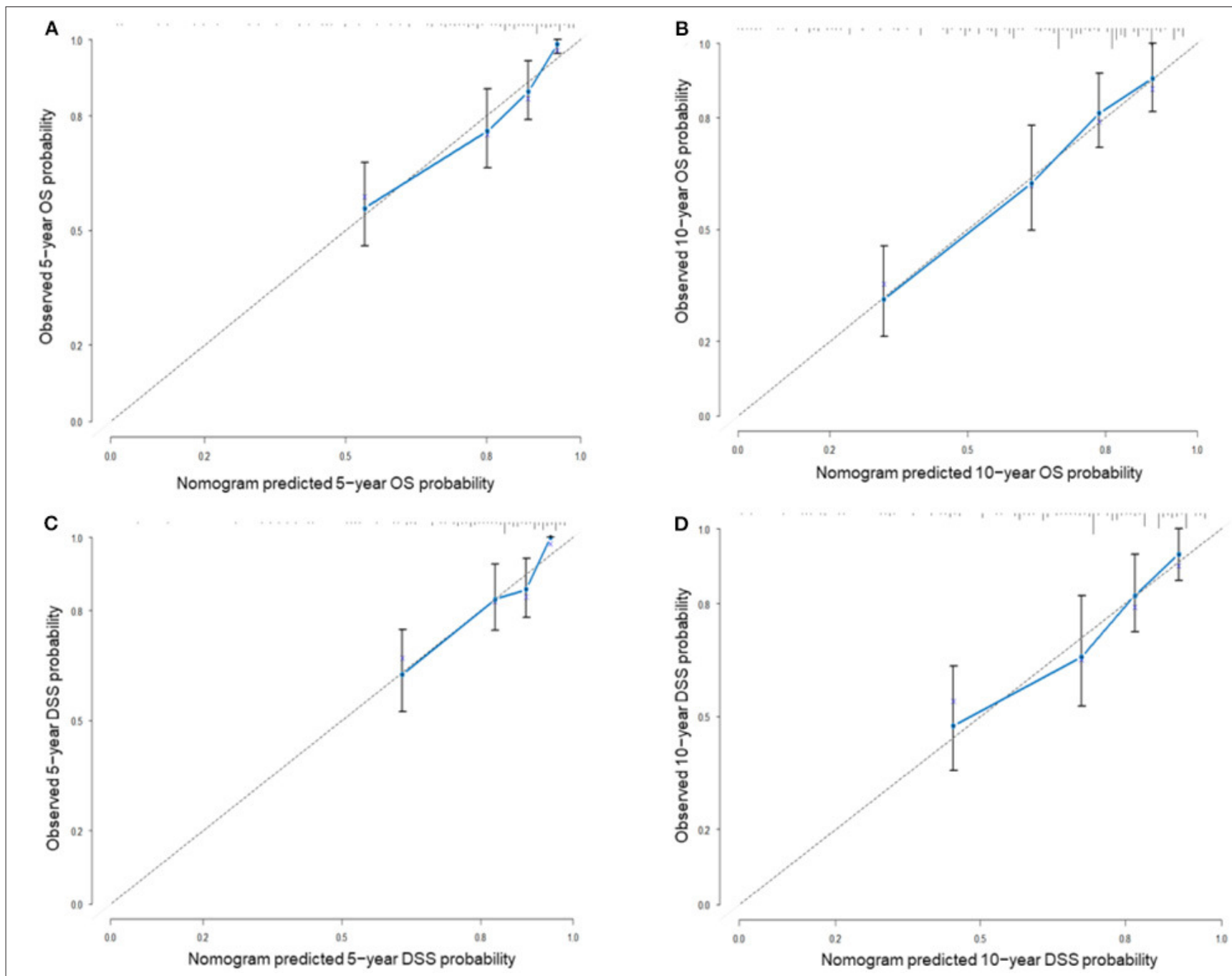

FIGURE 4 | The calibration plots for internal validation of (A) actual 5-year OS and (B) 10-year OS; (C) actual 5-year DSS and (D) actual 10-year DSS. The 45-degree dashed line represents an ideal match between the actual observed survival (Y-axis) and nomogram-predicted survival (X-axis). The perpendicular line represents $95 \%$ confidence intervals. Closer distances from the points to the dashed line mean a higher prediction accuracy.

(17). The larger the tumor, the more extensive is the scope of invasion. Thus, surgical resection becomes more difficult, with more complications, and the prognosis will be worse. Meanwhile, according to the staging method of $\mathrm{Wu}$, Stage I indicates that the tumor is primary and confined to a certain site. It is completely epidural, with no intracranial invasion and only mild neurological dysfunction. Stage II: the primary tumor is mainly epidural, but local dural invasion causes intracranial structure compression, with mild-to-moderate neurological dysfunction. Stage III: primary tumor growth is widespread, mostly invades subdural, compressing or adhering to the brain stem, with medium-to-severe neurological dysfunction. Stage IV: The tumor is metastatic, located either in the epidural or subdural, with or without neurological dysfunction (18). Although the staging method does not directly mention the relationship between tumor size and tumor staging, larger tumors are more likely to break through the dura, adhere to the brainstem and cause more severe neurological dysfunction (7). Furthermore, the closer the primary site of the tumor is to the brainstem or the vascular and nerve of the skull base, the greater the risk of treatment, with more complications and worse prognosis.

The prognosis of patients receiving surgical treatment was significantly better than that of patients without surgical treatment. However, analysis based on the SEER database found no statistically significant difference in OS between patients undergoing GTR and those undergoing STR after PSM. The results by validating data from the Xiangya Hospital also indicated that there was no statistical difference in OS between GTR and STR patients, but PFS could be improved. This suggests that GTR is not mandatory for skull base chordoma, and it is difficult to achieve safe resection, especially for tumors invading the subdural and adhering to the brainstem or important nerves and vessels. Forced GTR may cause serious postoperative complications, and lead to a worse prognosis $(20,23)$. At the 
TABLE 5 | Characteristics of 37 patients with skull base chordoma treated in Xiangya Hospital (2010-2020).

\begin{tabular}{lc}
\hline Age (years) & \\
Mean (SD) & $46.8(12.4)$ \\
Median [Min, Max] & $48.0[13.0,68.0]$ \\
Gender & \\
Female & $15(40.5 \%)$ \\
Male & $22(59.5 \%)$ \\
Histological subtype & \\
$\quad$ Chordoma & $37(100 \%)$ \\
Primary site & \\
$\quad$ Bones of skull & $18(48.6 \%)$ \\
$\quad$ Brain & $7(18.9 \%)$ \\
Pituitary gland & $12(32.4 \%)$ \\
Disease stage & \\
Distant & $7(18.9 \%)$ \\
Local & $5(13.5 \%)$ \\
Region & $25(67.6 \%)$ \\
Surgery & \\
GTR & $13(35.1 \%)$ \\
STR & $24(64.9 \%)$ \\
Radiation & \\
None & $15(40.5 \%)$ \\
Radiation after surgery & $22(59.5 \%)$ \\
Tumor size (cm) & \\
Mean (SD) & $4.11(1.21)$ \\
Median [Min, Max] & $4.00[2.30,8.00]$ \\
\hline GTR &
\end{tabular}

GTR, gross total resection; STR, subtotal resection.

same time, according to the therapeutic guidelines of skull base chordoma, if the total resection of the tumor is difficult, the purpose of surgery is to relieve the compression of the tumor on the brain stem and optic pathway, reduce the tumor volume, and lay the foundation for improving the efficacy of subsequent radiotherapy (24). Therefore, it should be advocated to remove as many tumors as possible under the premise of safety. At present, endoscopy is increasingly applied to the surgical treatment of skull base chordoma. Endoscopy can show locations that cannot be observed by microscope, providing a better vision for safe and thorough resection of tumors $(6,25-27)$. Staged resection can be performed for some tumors with a wide range of growth. Recently, some neurosurgeons have tried simultaneous combined surgery, combining transnasal and transcranial approaches with endoscopy, which can improve the safety and timeliness of surgery $(28,29)$. Moreover, intraoperative vascular ultrasound, neuronavigation, and neuroelectrophysiological monitoring can improve the accuracy and safety of surgery $(30,31)$.

The SEER database analysis showed that postoperative radiotherapy for prognosis improvement was not statistically significant, consistent with previous reports that chordoma was not sensitive to ordinary radiotherapy, mainly because it could not reach the effective radiation dose (32). However, according to the current treatment guidelines and expert consensus, adjuvant radiotherapy should be performed in patients with skull base chordoma after surgery, especially for patients who did not achieve total resection of the tumor. Our study based on the clinical data from the Xiangya Hospital found that although postoperative radiotherapy could not improve the OS rate, it could significantly prolong the PFS and had a positive effect on reducing the recurrence rate. With the development and popularization of new radiotherapy techniques, especially stereotactic radiotherapy and three-dimensional conformal radiotherapy, radiotherapy is more accurate for lesions, which increases the dose of tumor irradiation and reduces the damage to the surrounding normal brain tissue and cranial nerves $(33,34)$. Furthermore, proton beam radiotherapy or proton plus photon radiotherapy also has a good therapeutic effect on chordoma (35-38). Numerous studies have suggested that neo-adjuvant radiotherapy, as adjuvant therapy, can control the local recurrence of tumors to a certain extent and improve the prognosis of patients when the chordoma is subtotally resected or the resection margin is not clean $(21,39)$.

Given the insensitivity of chordoma to conventional chemotherapy, molecular targeted therapy is particularly important. Some recent studies have found that molecular targeting technology has a good prospect in the treatment of chordoma. At present, the research on the molecular mechanism of chordoma mainly includes receptor tyrosine kinase and its downstream signaling pathways, Src/Stat3 signaling pathway and PI3K/AKT/mTOR pathway (40-44). Many clinical studies on tyrosine kinase inhibitors, such as imatinib and erlotinib, suggested that tyrosine kinase inhibitors may be the breakthrough in the treatment of chordoma $(45,46)$.

This study had some limitations. Since this was a retrospective study of the SEER database, some clinical data were not detailed enough, such as the description of the primary site of the tumor was not accurate enough, and the SEER database lacks postoperative images which may concern patients' privacy, it is impossible to confirm whether the resection range meets the clinical guidelines. Although our data from the Xiangya Hospital included relatively detailed image data, the sample number was limited due to the rare incidence of this disease. Hence, multicenter prospective cohort studies with large sample sizes are needed in the future.

\section{CONCLUSIONS}

The main factors affecting the prognosis of chordoma of the skull base include the age of the patients, tumor size, surgical treatment, primary site, and tumor stage $(5,6)$. The main treatment for skull base chordoma remains surgical resection. Survival analysis showed no significant difference between GTR and STR for OS, GTR can significantly improve PFS, but it is difficult to achieve safely total resection because of its close relationship with brain stem and important cranial nerves and vessels. Forced GTR may lead to serious postoperative complications and affect the prognosis of patients. Therefore, resection of the tumor as much as possible 


\section{A}

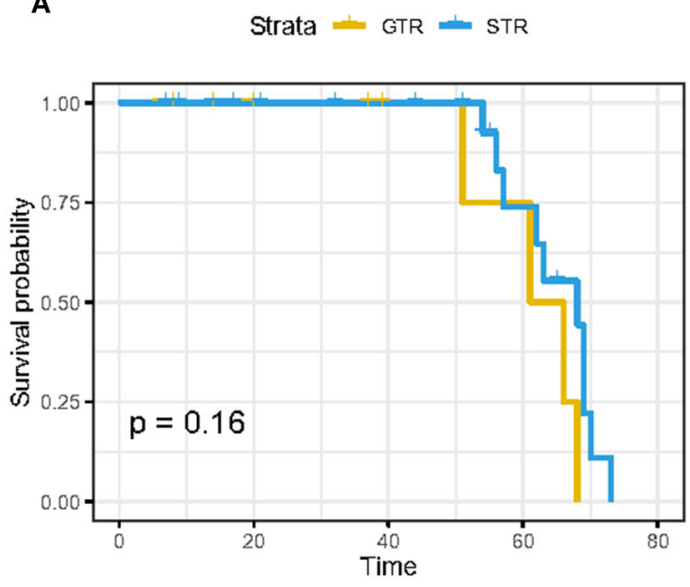

C

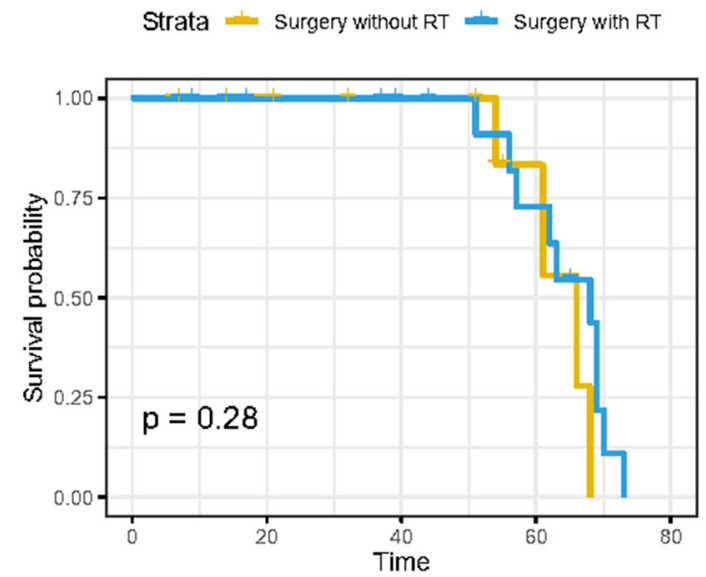

B

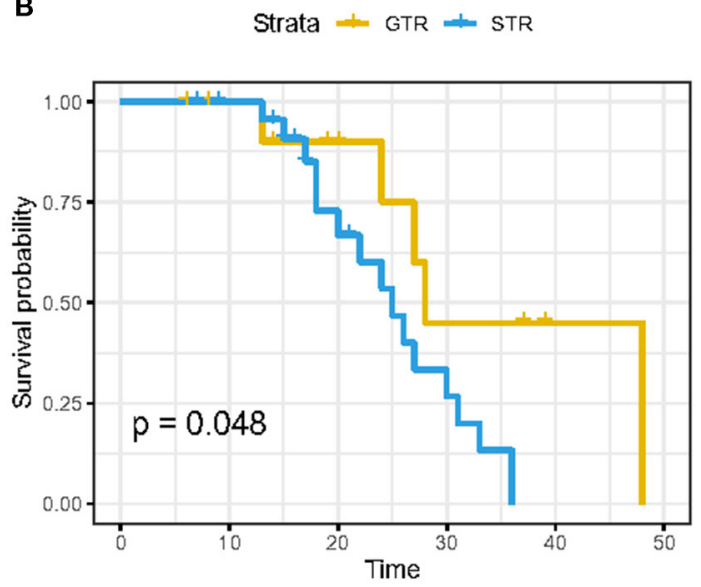

D

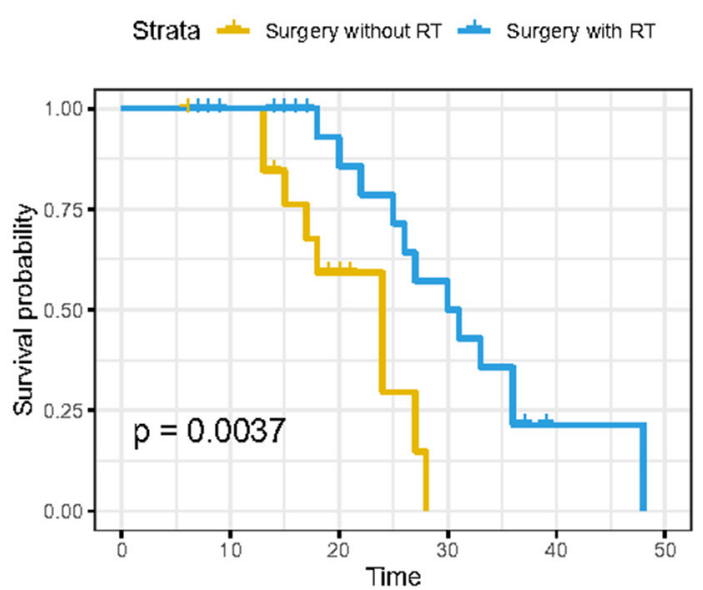

FIGURE 5 | Kaplan-Meier curves of OS in patients from Xiangya Hospital stratified by (A) gross total resection (GTR) and subtotal resection (STR), (C) surgery with radiotherapy and surgery without radiotherapy; K-M curves of progression-free survival in patients from Xiangya Hospital stratified by (B) GTR and STR and (D) surgery with radiotherapy and surgery without radiotherapy.

while ensuring safety, combined with postoperative neoadjuvant radiotherapy may be an ideal treatment for skull base chordoma. In addition, molecular targeted therapy is a very promising and important treatment for chordoma in the future.

\section{DATA AVAILABILITY STATEMENT}

The raw data supporting the conclusions of this article will be made available by the authors, without undue reservation.

\section{ETHICS STATEMENT}

The studies involving human participants were reviewed and approved by Ethics Committee of Xiangya Hospital of Central South University. Written informed consent to participate in this study was provided by the participants' legal guardian/next of kin.

\section{AUTHOR CONTRIBUTIONS}

CT conceived and designed the experiments, collected the data, prepared tables, authored and reviewed drafts of the article, and approved the final draft. QY and ZX analyzed the data, prepared figures and tables, and approved the final draft. NY prepared figures and tables and approved the final draft. XL conceived and designed the experiments, authored and reviewed drafts of the article, and approved the final draft. All authors contributed to the article and approved the submitted version.

\section{FUNDING}

This work was supported by the National Natural Science Foundation of China (for XL, Grant Nos. 81770781 and 81472594) and Natural Science Foundation of Hunan Province, China (Grant No. 2019JJ50978). 


\section{ACKNOWLEDGMENTS}

The authors thank the SEER program for providing the clinical data of chordoma, and all data obtained from

\section{REFERENCES}

1. Frezza AM, Botta L, Trama A, Dei Tos AP, Stacchiotti S. Chordoma: update on disease, epidemiology, biology and medical therapies. Curr Opin Oncol. (2019) 31:114-20. doi: 10.1097/CCO.0000000000000502

2. McMaster ML, Goldstein AM, Bromley CM, Ishibe N, Parry DM. Chordoma: incidence and survival patterns in the United States, 1973-1995. Cancer Causes Control. (2001) 12:1-11. doi: 10.1023/A:1008947301735

3. Weber AL, Brown EW, Hug EB, Liebsch NJ. Cartilaginous tumors and chordomas of the cranial base. Otolaryngol Clin North Am. (1995) 28:453-71. doi: 10.1016/S0030-6665(20)30514-4

4. Tai PT, Craighead P, Bagdon F. Optimization of radiotherapy for patients with cranial chordoma. A review of dose-response ratios for photon techniques. Cancer. (1995) 75:749-56.

5. Chambers KJ, Lin DT, Meier J, Remenschneider A, Herr M, Gray ST. Incidence and survival patterns of cranial chordoma in the United States. Laryngoscope. (2014) 124:1097-102. doi: 10.1002/lary.24420

6. Gui S, Zong X, Wang X, Li C, Zhao P, Cao L, et al. Classification and surgical approaches for transnasal endoscopic skull base chordoma resection: a 6-year experience with 161 cases. Neurosurg Rev. (2016) 39:321-32; discussion 32-3. doi: 10.1007/s10143-015-0696-1

7. Brito da Silva H, Straus D, Barber JK, Rostomily RC, Ferreira M Jr, Sekhar LN. Cranial chordoma: a new preoperative grading system. Neurosurgery. (2018) 83:403-15. doi: 10.1093/neuros/nyx423

8. Horbinski C, Oakley GJ, Cieply K, Mantha GS, Nikiforova MN, Dacic S, et al. The prognostic value of Ki-67, p53, epidermal growth factor receptor, 1p36, 9p21, 10q23, and 17p13 in skull base chordomas. Arch Pathol Lab Med. (2010) 134:1170-6. doi: 10.5858/2009-0380-OA.1

9. Liu JQ, Zhang QH, Wang ZL. Clinicopathological significance of p16, cyclin D1, Rb and MIB-1 levels in skull base chordoma and chondrosarcoma. World J Otorhinolaryngol Head Neck Surg. (2015) 1:50-6. doi: 10.1016/j.wjorl.2015.09.005

10. Zou MX, Lv GH, Li J, She XL, Jiang Y. Upregulated human telomerase reverse transcriptase (hTERT) expression is associated with spinal chordoma growth, invasion and poor prognosis. Am J Transl Res. (2016) 8:516-29.

11. Jahangiri A, Chin AT, Wagner JR, Kunwar S, Ames C, Chou D, et al. Factors predicting recurrence after resection of clival chordoma using variable surgical approaches and radiation modalities. Neurosurgery. (2015) 76:17985; discussion 85-6. doi: 10.1227/NEU.0000000000000611

12. Yakkioui Y, van Overbeeke JJ, Santegoeds R, van Engeland M, Temel Y. Chordoma: the entity. Biochim Biophys Acta. (2014) 1846:655-69. doi: 10.1016/j.bbcan.2014.07.012

13. Zou Y, Neale N, Sun J, Yang M, Bai HX, Tang L, et al. Prognostic factors in clival chordomas: an integrated analysis of 347 patients. World Neurosurg. (2018) 118:e375-87. doi: 10.1016/j.wneu.2018.06.194

14. Fischbein NJ, Kaplan MJ, Holliday RA, Dillon WP. Recurrence of clival chordoma along the surgical pathway. AJNR Am J Neuroradiol. (2000) 21:57883.

15. Jägersberg M, El Rahal A, Dammann P, Merkler D, Weber DC, Schaller K. Clival chordoma: a single-centre outcome analysis. Acta Neurochir. (2017) 159:1815-23. doi: 10.1007/s00701-017-3163-7

16. Crockard HA, Cheeseman A, Steel T, Revesz T, Holton JL, Plowman N, et al. A multidisciplinary team approach to skull base chondrosarcomas. J Neurosurg. (2001) 95:184-9. doi: 10.3171/jns.2001.95.2.0184

17. al-Mefty O, Borba LA. Skull base chordomas: a management challenge. $J$ Neurosurg. (1997) 86:182-9. doi: 10.3171/jns.1997.86.2.0182

18. Wu Z, Zhang J, Zhang L, Jia G, Tang J, Wang L, et al. Prognostic factors for long-term outcome of patients with surgical resection of skull base chordomas-106 cases review in one institution. Neurosurg Rev. (2010) 33:4516. doi: 10.1007/s10143-010-0273-6
SEER has been used by following the rules for usage and publication of SEER. We also thank the Medical Record Information Department of Xiangya Hospital for their help.
19. Thieblemont C, Biron P, Rocher F, Bouhour D, Bobin JY, Gérard JP, et al. Prognostic factors in chordoma: role of postoperative radiotherapy. Eur J Cancer. (1995) 31a:2255-9. doi: 10.1016/0959-8049(95)00458-0

20. Champagne PO, Passeri T, Jabre R, Bernat AL, Voormolen EH, Froelich S. Vertebrobasilar artery encasement by skull base chordomas: surgical outcome and management strategies. Oper Neurosurg (Hagerstown). (2020) 19:375-83. doi: 10.1093/ons/opaa091

21. Stacchiotti S, Gronchi A, Fossati P, Akiyama T, Alapetite C, Baumann M, et al. Best practices for the management of local-regional recurrent chordoma: a position paper by the Chordoma Global Consensus Group. Ann Oncol. (2017) 28:1230-42. doi: 10.1093/annonc/mdx054

22. Pan Y, Lu L, Chen J, Zhong Y, Dai Z. Analysis of prognostic factors for survival in patients with primary spinal chordoma using the SEER registry from 1973 to 2014. J Orthop Surg Res. (2018) 13:76. doi: 10.1186/s13018-018-0784-3

23. Wang L, Wu Z, Tian K, Wang K, Li D, Ma J, et al. Clinical features and surgical outcomes of patients with skull base chordoma: a retrospective analysis of 238 patients. J Neurosurg. (2017) 127:1257-67. doi: 10.3171/2016.9.JNS 16559

24. Biermann JS, Chow W, Reed DR, Lucas D, Adkins DR, Agulnik M, et al. NCCN guidelines insights: bone cancer, Version 2.2017. J Natl Compr Canc Netw. (2017) 15:155-67. doi: 10.6004/jnccn.2017.0017

25. Mangussi-Gomes J, Beer-Furlan A, Balsalobre L, Vellutini EA, Stamm AC. Endoscopic endonasal management of skull base chordomas: surgical technique, nuances, and pitfalls. Otolaryngol Clin North Am. (2016) 49:16782. doi: 10.1016/j.otc.2015.09.011

26. Yumiko O, Tamura R, Takahashi S, Morimoto Y, Sato M, Horikoshi $\mathrm{T}$, et al. A comparative study between traditional microscopic surgeries and endoscopic endonasal surgery for skull base chordomas. World Neurosurg. (2020) 134:e1099-107. doi: 10.1016/j.wneu.2019. 11.113

27. Schwartz TH, Morgenstern PF, Anand VK. Lessons learned in the evolution of endoscopic skull base surgery. J Neurosurg. (2019) 130:337-46. doi: 10.3171/2018.10.JNS182154

28. Koechlin NO, Simmen D, Briner HR, Reisch R. Combined transnasal and transcranial removal of a giant clival chordoma. J Neurol Surg Rep. (2014) 75:e98-102. doi: 10.1055/s-0034-1373668

29. Shkarubo AN, Andreev DN, Konovalov NA, Lubnin AY, Zelenkov PV, Turkin $\mathrm{AM}$, et al. The algorithm for surgical treatment of skull base tumors invading the craniovertebral junction. Zh Vopr Neirokhir Im N N Burdenko. (2016) 80:21-34. doi: 10.17116/neiro201680221-34

30. Hwang PY, Ho CL. Neuronavigation using an image-guided endoscopic transnasal-sphenoethmoidal approach to clival chordomas. Neurosurgery. (2007) 61(Suppl. 2):212-7; discussion 7-8. doi: 10.1227/01.neu.0000303219.55 393.fe

31. Wang $\mathrm{X}, \mathrm{Li} \mathrm{L}$, Wang $\mathrm{Y}, \mathrm{Hu} \mathrm{J}$, Zhou J, Jing $\mathrm{Z}$, et al. Clinical application of multimodal neuronavigation system in neuroendoscope-assisted skull base chordoma resection. J Craniofac Surg. (2017) 28:e554-7. doi: 10.1097/SCS.00000000000 03859

32. Casali PG, Stacchiotti S, Sangalli C, Olmi P, Gronchi A. Chordoma. Curr Opin Oncol. (2007) 19:367-70.. doi: 10.1097/CCO.0b013e3281214448

33. Kano H, Niranjan A, Lunsford LD. Radiosurgery for chordoma and chondrosarcoma. Prog Neurol Surg. (2019) 34:207-14. doi: 10.1159/000493066

34. Vasudevan HN, Raleigh DR, Johnson J, Garsa AA, Theodosopoulos PV, Aghi MK, et al. Management of chordoma and chondrosarcoma with fractionated stereotactic radiotherapy. Front Surg. (2017) 4:35. doi: 10.3389/fsurg.2017.00035

35. Noel G, Gondi V. Proton therapy for tumors of the base of the skull. Chin Clin Oncol. (2016) 5:51. doi: 10.21037/cco.2016.07.05 
36. Baumann BC, Lustig RA, Mazzoni S, Grady SM, O’Malley BW, Lee JYK, et al. A prospective clinical trial of proton therapy for chordoma and chondrosarcoma: feasibility assessment. J Surg Oncol. (2019) 120:200-5. doi: 10.1002 /jso. 25502

37. Unkelbach J, Bangert M, De Amorim Bernstein K, Andratschke N, Guckenberger M. Optimization of combined proton-photon treatments. Radiother Oncol. (2018) 128:133-8. doi: 10.1016/j.radonc.2017.12.031

38. Fossati P, Vavassori A, Deantonio L, Ferrara E, Krengli M, Orecchia R. Review of photon and proton radiotherapy for skull base tumours. Rep Pract Oncol Radiother. (2016) 21:336-55. doi: 10.1016/j.rpor.2016. 03.007

39. Walcott BP, Nahed BV, Mohyeldin A, Coumans JV, Kahle KT, Ferreira MJ. Chordoma: current concepts, management, and future directions. Lancet Oncol. (2012) 13:e69-76. doi: 10.1016/S1470-2045(11)70337-0

40. Fasig JH, Dupont WD, LaFleur BJ, Olson SJ, Cates JM. Immunohistochemical analysis of receptor tyrosine kinase signal transduction activity in chordoma. Neuropathol Appl Neurobiol. (2008) 34:95-104. doi: 10.1111/j.1365-2990.2007.00873.x

41. Akhavan-Sigari R, Abili M, Gaab MR, Rohde V, Zafar N, Emami P, et al. Immunohistochemical expression of receptor tyrosine kinase PDGFR- $\alpha$, c-Met, and EGFR in skull base chordoma. Neurosurg Rev. (2015) 38:89-98; discussion 98-9. doi: 10.1007/s10143-0140579-x

42. Tamborini E, Virdis E, Negri T, Orsenigo M, Brich S, Conca E, et al. Analysis of receptor tyrosine kinases (RTKs) and downstream pathways in chordomas. Neuro Oncol. (2010) 12:776-89. doi: 10.1093/neuonc/noq003

43. Yang C, Hornicek FJ, Wood KB, Schwab JH, Choy E, Mankin H, et al. Blockage of Stat3 with CDDO-Me inhibits tumor cell growth in chordoma. Spine. (2010) 35:1668-75. doi: 10.1097/BRS.0b013e3181c2d2b4
44. Michmerhuizen NL, Owen JH, Heft Neal ME, Mann JE, Leonard E, Wang J, et al. Rationale for the advancement of PI3K pathway inhibitors for personalized chordoma therapy. J Neurooncol. (2020) 147:25-35. doi: 10.1007/s11060-020-03418-7

45. Hindi N, Casali PG, Morosi C, Messina A, Palassini E, Pilotti S, et al. Imatinib in advanced chordoma: a retrospective case series analysis. Eur J Cancer. (2015) 51:2609-14. doi: 10.1016/j.ejca.2015.07.038

46. Meng T, Jin J, Jiang C, Huang R, Yin H, Song D, et al. Molecular Targeted therapy in the treatment of chordoma: a systematic review. Front Oncol. (2019) 9:30. doi: 10.3389/fonc.2019.00030

Conflict of Interest: The authors declare that the research was conducted in the absence of any commercial or financial relationships that could be construed as a potential conflict of interest.

Publisher's Note: All claims expressed in this article are solely those of the authors and do not necessarily represent those of their affiliated organizations, or those of the publisher, the editors and the reviewers. Any product that may be evaluated in this article, or claim that may be made by its manufacturer, is not guaranteed or endorsed by the publisher.

Copyright (c) 2021 Teng, Yang, Xiong, Ye and Li. This is an open-access article distributed under the terms of the Creative Commons Attribution License (CC BY). The use, distribution or reproduction in other forums is permitted, provided the original author(s) and the copyright owner(s) are credited and that the original publication in this journal is cited, in accordance with accepted academic practice. No use, distribution or reproduction is permitted which does not comply with these terms. 